\title{
Presentación
}

\section{Biograficidad y Educación}

\author{
Francesc J. Hernàndez y Eugenia Cardenal ${ }^{1}$
}

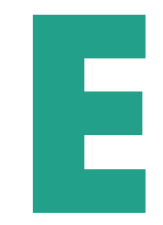

1 término «educación», en Sociología, ha tenido, casi desde sus orígenes, un significado que, como señala Fernández Enguita (1998), abarca tres dimensiones:

1. Se trata de un proceso de «fuera» (la sociedad) a «adentro» (el individuo).

2. Este proceso no se refiere sólo a los conocimientos transmitidos, sino que abarca la totalidad del individuo.

3. La educación busca la incorporación del individuo (particular) a la sociedad (general).

Esta concepción de la educación arranca de Durkheim, quien en su conocido ensayo «La educación, su naturaleza y su papel» afirmaba:

"La educación es la acción ejercida por las generaciones adultas sobre aquéllas que aún no han alcanzado el grado de madurez necesario para la vida social. Tiene por objeto el suscitar y desarrollar en el niño un cierto número de estados físicos, intelectuales y morales que exigen de él tanto la sociedad política en su conjunto como el medio ambiente específico al que está especialmente destinado». (1989, p. 53. Ed. original 1922).

La educación, es, así definida, un proceso unidireccional de producción de orden social, en el que los individuos se convierten en sujetos en la medida en que se configura en ellos una subjetividad conforme al sistema del que están destinados a formar parte (Dubet y Martuccelli, 2005: 201-202). En el actual escenario de desregulación de los modos institucionalizados de integración y normalización social propios del keynesiano-fordismo, esta concepción de la educación debe ser revisada. La familia y la escuela han perdido el monopolio de la transmisión de conocimientos ideas y valores, y, con ello, buena parte de su autoridad; la escuela universal supone un alumnado mucho más heterogéneo, que cuestiona la norma social del «buen alumno» que interioriza sin rechistar los modos de hacer y pensar de las clases intelectuales. A ello hay que añadir que la fragmentación y precarización laboral han deslegitimado la promesa meritocrática, hoy más difícil de cumplir que en los tiempos de auge del capitalismo regulado: los calificados como «buenos alumnos» del sistema de enseñanza tienen un acceso muy complejo y arduo, cuando no inviable, a los trabajos y las posiciones sociales que, se supone, se han ganado (Cardenal de la Nuez, 2016).

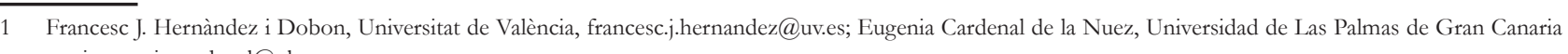
mariaeugenia.cardenal@ulpgc.es. 
La educación, pues, tanto en su dimensión cognitiva como en su dimensión moral y emocional, pasa a ser vista como un proceso de aprendizaje (Dubet, 2006), donde el sujeto es agente e interactúa en distintos espacios sociales, desde una posición social, desde luego, pero con un componente mayor de incertidumbre respecto al resultado de sus decisiones, y con una importante interiorización de su responsabilidad como agente activo de su proceso vital.

La legitimidad actual del análisis biográfico en el panorama sociológico descansa, en buena medida, en la constatación de estas transformaciones sociales, que colocan al individuo reflexivo en el centro de la escena social, empujándole a tomar decisiones y a interpretar constantemente las oportunidades y limitaciones a su alcance. Desde el análisis biográfico, la educación es vista como una «escritura de vida», como decisiones en el curso de la vida (Hernàndez y Víllar, 2015: 427) en tensión dialéctica con el entorno. Es aquí donde entra en juego la noción de biograficidad. Como señala Alheit,

«Biograficidad significa que podemos plantearnos nuevamente, una y otra vez, nuestra vida en los contextos en los que nosotros pasamos (tenemos que pasar) la vida, y que experimentamos estos contextos como "formables" y configurables. No tenemos en nuestra biografía todas las oportunidades imaginables, pero en el marco de los límites de los estructuralmente establecidos tenemos abiertos considerables espacios de posibilidad». (Alheit, 2015: 58).

Los autores que escriben en este Monográfico analizan la relación entre biograficidad y educación desde perspectivas tanto teóricas como empíricas. Entre las teóricas, destacan las aportaciones internacionales, empezando por el trabajo de Arnold, que subraya la necesidad de un concepto de aprendizaje contemporáneo, proponiendo una problematización del concepto «formación» o del nexo entre «enseñanza» y «aprendizaje». Para ello, propone ubicar lo biográfico en el centro de lo educativo. Postula, así una formación de la personalidad, un programa que tiene que ver más con los propios rastros emocionales de los seres humanos en sus fases biográficas de desarrollo que con los contenidos de los planes de estudio y curricula. Stauber, por su parte, analiza la relación dialéctica entre la «biograficidad de lo social» y la «socialidad de lo biográfico» tal y como es planteada por Dausien (2008), para proponer un análisis de las potencialidades de la entrevista biográfica como expresión del sujeto, que se manifiesta no solo en el «qué», sino también en el «cómo». Basándose en las aportaciones de Foucault y de Butler, la autora plantea que en el «cómo», la dimensión performativa de la entrevista, reside la posibilidad de resignificación, que anuncia el potencial transformativo de todo proceso biográfico. El artículo de Cardenal y Hernàndez, desde España, muestra cómo las corrientes sociológicas más importantes, la corriente comprensiva y la corriente crítica, dejaron de lado la investigación biográfica. Aunque la hermenéutica de Schleiermacher permitía la investigación de la generalidad en la particularidad, fue la introducción del «grado de evidencia» por parte de Weber la que orientó la corriente comprensiva hacia el funcionalismo estructuralista. El trabajo de Alheit, se centra en el amplio rango de las concepciones formativas orientadas biográficamente. La amplitud de los planteamientos va desde intervenciones terapéuticas individuales hasta el compromiso sociopolítico, desde temas clásicos de la formación continua de índole general y sociocultural, hasta las nuevas cuestiones de formación continua profesional y política. Por lo tanto, concluye el autor, la orientación de la biografía en la formación de personas (adultas) puede considerarse como una especie de "paradigma oculto» que, además, sugiere un cambio gradual en las disposiciones de los profesionales. Precisamente son estas disposiciones las que constituyen el foco de interés del artículo de Leal da Costa, Biscaia y Argüello, a medio camino entre el análisis teórico y el empírico. El trabajo fundamenta el desarrollo del «Atelier Biográfico de Proyecto» (ABP) durante el curso académico 
2017/2018 y presenta las experiencias vividas. El atelier fue creado como un dispositivo pedagógico en el contexto de la formación de Máster en Educación Infantil de la Universidad de Évora. El examen de los documentos producidos durante el Atelier lleva a los autores a reflexionar sobre los procesos de construcción de identidad profesional que se desarrollan en la institución universitaria.

En cuanto a los trabajos netamente empíricos, en ellos identificamos una gran variedad de temas, tanto entre las aportaciones internacionales como entre las realizadas por autoras y autores españoles. En el ámbito internacional, el artículo de Christodoulou, Bousia y Kiprianos analiza el rol de las emociones en la conformación de la identidad profesional. Los autores estudian las trayectorias biográficas de profesoras y profesores de Formación Profesional que despedidos en Grecia los dos años del «memorándum». Mediante entrevistas biográfico-narrativas, y, utilizando el paradigma del realismo crítico, describen cómo las dinámicas emocionales creadas minaron su sentido de pertenencia a la profesión. En otro país fuertemente golpeado por la crisis, Portugal, Vieira se centra en la escolarización como un (nuevo) lazo de filiación que vincula a padres e hijos, y se ocupa de una competencia parental crecientemente valorada: la participación activa en la biografía escolar de los hijos, denominada life coaching. Su objetivo es examinar específicamente los desafíos y las ambivalencias del apoyo parental a la elección vocacional de los hijos en un contexto de incertidumbre, y en un momento de importante «desafío biográfico» de los hijos: la elección de estudios secundarios. En Italia, Santagati examina las rutas escolares de los alumnos de origen inmigrante con rendimiento académico positivo y un proyecto educativo y biográfico, de éxito, con el fin de investigar las implicaciones de este fenómeno desde un punto de vista teórico, metodológico y empírico. Después de una revisión de los principales estudios sociológicos sobre el «optimismo inmigrante» hacia el éxito educativo, la autora reflexiona sobre el enfoque biográfico, particularmente adecuado para este tema. Finalmente, en el artículo se presenta un proyecto de investigación basado en autobiografías educativas de estudiantes de secundaria de origen inmigrante que transitaron con éxito por escuela secundaria superior en Italia, centrándose en el caso de Destiny, una estudiante de origen marroquí.

En España, y concretamente en Zaragoza, López Rodríguez y Sanz Hernández plantean una reflexión acerca de las trayectorias vitales de mujeres gitanas. Las entrevistadas acumulan aprendizajes informales y formales que constituyen el sentido de identidad. Los primeros durante la enculturación, con el grupo de referencia que define su identidad como mujer gitana en el paradigma tradicional. Los segundos durante la socialización, mientras se alejan de la línea de cruce y permanecen en el sistema educativo y laboral: en el paradigma de la modernidad, compartiendo significados con coetáneos y congéneres. El resultado es una identidad compleja, moldeada en la doble dimensión individual y social en espacios culturales y marcos sociales diversos. El trabajo de Sanvicén se centra en la recuperación y visibilización de las trayectorias vitales de las mujeres que vivieron durante la Guerra Civil en las comarcas de Lleida, analizando de manera sistemática las únicas seis memorias escritas por ellas en ese periodo. Los resultados llevan a la autora a reivindicar el interés de incorporar los egodocumentos (textos narrativos en primera persona) de mujeres, como una tipología de fuentes formativas más allá de los grados y asignaturas de historia, especialmente en los de contenido sociológico. Finalmente, y en claro paralelismo con el estudio de Santagati, la investigación empírica realizada por Tarrés muestra el proceso educativo de dos jóvenes menores que viajaron de África a Europa, analizando sus construcciones biográficas, marcadas por el paso de sociedad de origen a sociedad de destino. El relato y la representación gráfica de la trayectoria vivida aportan elementos de reflexión sobre el encauzamiento del alumnado de incorporación tardía en nuestra sociedad. Ambas biografías se extraen de una investigación llevada a cabo en Cataluña, cuyo ob- 
jetivo es conocer qué hace posible la progresión educativa exitosa del alumnado de incorporación tardía que vive en contextos vulnerables.

Los artículos recopilados muestran, en definitiva, la heterogeneidad temática y amplitud geográfica que abarca, hoy en día, el ámbito de análisis biográfico en el campo de la Educación. Y también revelan la importancia de la biograficidad en la formación de los futuros educadores, destinados, ellos también, a convertirse en agentes reflexivos de su propia realidad y de la de su futuro alumnado.

\section{Referencias bibliográficas}

Alheit, Peter (2015): “¿Identidad o biograficidad?” en Francesc J. Hernández y Alícia Víllar (eds.): Educación y biografías. Perspectivas pedagógicas y sociológicas actuales. Barcelona: UOC.

Cardenal de la Nuez, María Eugenia (2016): "Lola's Story: The Struggle to Build a Professional Identity with No Good Jobs in Sight" in Rina Benmayor, María Eugenia Cardenal de la Nuez y Pilar Domínguez Prats (eds.): Memory, Subjectivities, and Representation. Approaches to Oral History in Latin America, Portugal, and Spain. New York: Palgrave Macmillan.

Dausien, Bettina (2008). Sozialisation - Geschlecht-Biographie. Theoretische Diskurse und Forschungsperspektiven. Wiesbaden: VS Verlag für Sozialwissenschaften.

Dubet, François (2006). El declive de la institución. Profesiones, sujetos e individuos en la modernidad. Barcelona: Gedisa.

Dubet, François y Martuccelli, Danilo (2005). ¿En qué sociedad vivimos? Barcelona: Losada.

Durkheim, Émile (1989): “La educación, su naturaleza y su papel” en Émile Durkheim (ed.): Educación y Sociología. Barcelona: Península, 1922.

Fernández Enguita, Mariano (1988): Voz “Educación” en Salvador Giner, Emilio Lamo de Espinosa y Cristóbal Torres (eds.): Diccionario de Sociología. Madrid: Alianza.

Hernàndez, Francesc J. y Villar, Alícia (2015): “Aproximación sociológica a la relación entre educación y biografías. Corrientes teóricas actuales y aportaciones empíricas" en Francesc J. Hernàndez y Alícia Villar (eds.): Educación y biografías. Perspectivas pedagógicas y sociológicas actuales. Barcelona: UOC. 